\title{
PROTEÇÃO CONTRA INCÊNDIO: UMA ANÁLISE DIAGNÓSTICA DO PLANO DE \\ EMERGÊNCIA DO BLOCO D DA UNIARP
}

Thais Cristina Tieppo ${ }^{1}$

Liane da Silva Bueno ${ }^{2}$

\section{RESUMO}

Este artigo aborda a respeito da verificação dos pré-requisitos para edificações em relação a prevenção de incêndios, segundo as Normativas do corpo de Bombeiros do Estado de Santa Catarina, como projetos preventivos de incêndio, extintores, luminárias de emergência, entre outros. Portanto, propõe-se um levantamento in loco, bem como uma análise diagnóstica do bloco D da Universidade Alto Vale do Rio do Peixe - UNIARP, Campus Caçador, afim de identificar o cumprimento dos critérios normatizados. Bem como, sugestões para a UNIARP, referente aos treinamentos e informações necessárias aos colaboradores e alunos da instituição, quanto a possíveis situações de incêndio que possa comprometer a saúde e integridade física dos ocupantes.

Palavras-Chave: Plano de Emergência. Incêndio. Evacuação.

\section{ABSTRACT}

This article discusses the verification of the prerequisites for buildings in relation to fire prevention, according to the Regulations of the Fire Department of the State of Santa Catarina, such as preventive fire projects, extinguishers, and emergency luminaires, among others. Therefore, an on-site survey is proposed, as well as a diagnostic analysis of block D of the Universidad Alto Vale do Rio do Peixe-UNIARP, Campus Caçador, identify compliance with standard criteria. As well as suggestions

\footnotetext{
${ }^{1}$ Formanda do curso de Engenharia Civil da Universidade Alto Vale do Rio do Peixe (UNIARP).Email: thaisttieppo@gmail.com

${ }^{2}$ Doutora em Engenharia de Produção. Mestre em Enga. Civil. Engenheira Civil. Docente no curso de Enga. Civil da UNIARP. Email: lianebueno@gmail.com
} 
for UNIARP, regarding the training and information necessary for the institution's employees and students, possible fire situations that could compromise the health and physical integrity of occupants.

Keywords: Emergency plan. Fire. Evacuation.

\section{INTRODUÇÃO}

O Incêndio é caracterizado como a destruição causada pelo fogo propriamente dito, somente acontece com um conjunto de elementos chamado de reação em cadeia, na qual é composta de quatro elementos sendo eles combustível, por exemplo, gasolina, um comburente, que seria o oxigênio presente no ar, uma fonte de calor, podendo ser uma faísca, ou qualquer outra fonte de calor conhecida no local, e por fim se dá origem a reação em cadeia, que faz com que o fogo se torne intermitente (JUNIOR, 2013).

Em edificações que frequentam grande número de pessoas como é o caso do Bloco D da Universidade Alto Vale do Rio do Peixe - UNIARP, segundo a Norma IN 001 - Instrução Normativa (CORPO DE BOMBEIROS MILITARES DE SANTA CATARINA - CBMSC, 2015), para classificação de escolas em geral, independente da área ou ocupação deverá conter Plano de Emergência, Proteção por extintores, Saídas de Emergência, Iluminação de emergência, Sinalização para abandono de local, entre outros.

Portanto é de extrema importância fazer uma revisão do plano de emergência existente, pois, em casos de incêndios, através dele é que são elaborados os melhores métodos para controlar a situação. Segundo NBR 15219 (ASSOCIACAO BRASILEIRA DE NORMAS TECNICAS - ABNT, 2005) emergência é a Situação crítica que acontece por acaso e representa perigo à vida, ao meio ambiente e ao patrimônio, podendo gerar um dano continuado que obriga a uma imediata intervenção operacional, o plano de emergência é obrigatório para qualquer planta, com exceção das edificações residenciais unifamiliares.

Quantas vezes as pessoas entram no local e antes de encontrar seu destino final tentam identificar as saídas de emergência, qual a melhor saída se por um acaso houver um indício de incêndio, qual será a reação, quantas das edificações que você frequenta possui em local visível uma planta de emergência. 
Logo, surge o seguinte problema: Qual seria a melhor solução a ser adotada para o plano de emergência no Bloco D da UNIARP?

Através deste, devemos analisar os contextos e ter uma visão ampla e perceptível que um incêndio é imprevisível, e pode acontecer em qualquer lugar que frequentamos, você já deve ter ido ao cinema aonde antes de iniciar o filme eles anunciam aonde se encontram as saídas de emergência e uma breve explicação de como funciona o sistema de segurança do local. Este procedimento acontece para o público presente saber o que fazer em casos de incêndio e é de extrema importância que o mesmo seja revisado no Bloco $D$ da UNIARP pois existem diversos tipos de público com diferentes idades, e necessidades, merecendo um cuidado especial tanto com as pessoas ali presentes como para preservar a estrutura da edificação.

O objetivo geral será elaborar uma análise diagnóstica do plano de emergência no Bloco D da UNIARP, de acordo com as normas vigentes do Corpo de Bombeiros Militar de Santa Catarina. E os objetivos específicos são os que se referem abaixo:

a) Analisar a estrutura da edificação verificando se contém todos os equipamentos contra incêndio solicitados pela NSCl- Normas de Segurança Contra Incêndio vigente;

b) Verificar o funcionamento dos dispositivos de emergência;

c) Identificar as fragilidades do projeto preventivo contra incêndio bem como plano de emergência, de acordo com as normas vigentes do Corpo de Bombeiros Militar de Santa Catarina;

d) Propor sugestões para a UNIARP, referente aos treinamentos e informações pertinentes a situações de incêndio.

Assim sendo, este artigo propõe apresentar um estudo de caso, fundamentado a partir das normas vigentes direcionadas ao tema proposto, tal seja, prevenção de incêndio, a partir de uma análise diagnóstica do Plano de Emergência do Bloco D da UNIARP. Contudo, apresenta-se uma metodologia na qual veio subsidiar sugestões pertinentes, referente aos treinamentos e 
informações necessárias como resultado desta pesquisa.

\section{DESENVOLVIMENTO}

\section{EXIGÊNCIAS PARA O BLOCO D DA UNIARP CONFORME INSTRUÇÕES NORMATIVAS}

\section{DO CORPO DE BOMBEIROS MILITAR DE SANTA CATARINA}

Para prevenção do pânico em casos de incêndio, e a garantia de segurança das pessoas que frequentam o bloco D da UNIARP a Instrução normativa IN 001 (CBMSC, 2015) prevê algumas especificações, como saídas de emergência, sinalizações para abandono de local, iluminação de emergência, alarme e detecção de incêndio, plano de emergência, materiais de acabamento e revestimento etc., essas especificações irão depender do tipo do local a ser analisado, neste caso utilizaremos a especificação escolar geral, abaixo segue tabela demonstrativa:

Tabela 1 - Exigência dos sistemas e medidas de segurança contra incêndio e pânico em escolas em geral

\begin{tabular}{l|l}
\hline $\begin{array}{l}\text { Parâmetro } \\
\text { Mínimo }\end{array}$ & Sistema ou medida obrigatório \\
\hline Independente & Plano de emergência. \\
\hline Independente & Proteção por extintores. \\
\hline Independente & Saídas de emergência. \\
\hline Independente & Instalações de gás combustível (quando houver consumo de gás). \\
\hline Independente & $\begin{array}{l}\text { Iluminação de emergência e Sinalização para abandono do local nas } \\
\text { circulações, saídas de emergência, salas de aula (exceto quando a sala } \\
\text { possuir saída direta para o exterior), auditórios e elevadores. }\end{array}$ \\
\hline Independente & Materiais de acabamento e revestimento, ver IN 018/DAT/CBMSC \\
\hline Independente & Piscina de uso coletivo, atender a IN 033/DAT/CBMSC. \\
\hline $\mathrm{A} \geq 1500 m^{2}$ & Sistema de alarme e detecção de incêndio. \\
\hline $\mathrm{H} \geq 20 \mathrm{~m}$ ou & $\begin{array}{l}\text { Sistema de proteção contra descargas atmosféricas (pode ser } \\
\text { dispensado conforme a IN 010/DAT/CBMSC) }\end{array}$ \\
\hline $\mathrm{H} \geq 4$ pvtos ou & Sistema hidráulico preventivo \\
$\mathrm{A} \geq 750 m^{2}$ & Dispositivo para ancoragem de cabos \\
\hline $\mathrm{H}>20 \mathrm{~m}$ & Local para resgate aéreo \\
\hline $\mathrm{H}>40 \mathrm{~m}$ & Elevador de emergência \\
\hline $\mathrm{H}>60 \mathrm{~m}$ &
\end{tabular}

Fonte: Adaptado de IN 001 (CBMSC, 2015) 
INSTRUÇÕES NORMATIVAS X ANÁLISE DIAGNÓSTICA DO PLANO DE EMERGÊNCIA DO BLOCO D DA UNIARP

Para melhor entendimento das normativas utilizadas no presente estudo foram montadas listas de verificação referente a todo o sistema exigido pelo Corpo de Bombeiros Militar de Santa Catarina (CBMSC). Sendo utilizadas como base as Instruções Normativas (IN) listadas abaixo:

- IN 006 - Sistema de Proteção por Extintores (CBMSC, 2017);

- IN 007 - Sistema Hidráulico Preventivo (CBMSC, 2017),

- IN 009 - Sistema de Saída de Emergência (CBMSC, 2014);

- IN 011 - Sistema de lluminação de Emergência (CBMSC, 2017);

- IN 012 - Sistema de Alarme e detecção de incêndio (CBMSC, 2018);

- IN 013 - Sinalização para abandono de local (CBMSC, 2018);

- IN 018 - Controle de Materiais de Revestimento e Acabamento (CBMSC, 2016);

- IN 028 - Brigada de Incêndio (CBMSC, 2014);

- IN 031 - Plano de Emergência (CBMSC, 2014).

Após análise das normativas e confeç̧ão de listas de verificação especificas para cada IN proposta pelo CBMSC, foram realizadas as visitas in loco para possível preenchimento das listas elaboradas, bem como, pesquisas através de funcionários da Instituição de ensino que forneceram todos os dados necessários para melhor desenvolvimento do presente estudo.

\section{RESULTADOS E DISCUSSÃO}

Após aplicada a metodologia obteve-se resultados satisfatórios para análise diagnóstica do Bloco D da UNIARP, pontuando-se pontos positivos, bem como propostas de melhoria. Foram elaboradas Listas de Verificação dos critérios 
de prevenção de incêndios pontuados nas normativas vigentes citadas acima.

As Listas de Verificação, preenchidas durante as visitas in loco, proporcionaram identificar as divergências em relação as normativas atuais do Corpo de Bombeiros Militar de Santa Catarina.

Salientando-se que as listas de verificação apresentadas nas análises resultantes deste artigo serão direcionadas àquelas diagnosticadas como as que necessitam de melhorias.

Lista de Verificação referente ao plano de emergência em relação à IN 031 (CBMSC, 2014)

Quadro 1: Preenchimento Lista de Verificação de Plano de Emergência

\begin{tabular}{|c|c|c|c|}
\hline \multirow{2}{*}{ Procedimentos } & \multicolumn{2}{|c|}{ Enquadra } & \multirow{2}{*}{ Observações } \\
\hline & Sim & Não & \\
\hline Alerta de Emergência & $x$ & & Através do Alarme de Incêndio \\
\hline Análise da Situação & & $x$ & $\begin{array}{l}\text { Não foram identificadas pessoas } \\
\text { habilitadas }\end{array}$ \\
\hline Acionamento do CBMSC & $x$ & & \\
\hline Prestação de Primeiros Socorros & $\mathrm{x}$ & & Feito por possíveis alunos \\
\hline Identificação de Risco Existente & & $x$ & $\begin{array}{l}\text { Não foram identificadas pessoas } \\
\text { habilitadas }\end{array}$ \\
\hline Responsável de extinção dos Riscos & & $x$ & $\begin{array}{l}\text { Não foram identificadas pessoas } \\
\text { habilitadas }\end{array}$ \\
\hline Eliminação de Riscos & & $x$ & $\begin{array}{l}\text { Não foram identificadas pessoas } \\
\text { habilitadas }\end{array}$ \\
\hline Abandono de Área & & $x$ & $\begin{array}{l}\text { Não foram identificadas pessoas } \\
\text { habilitadas }\end{array}$ \\
\hline Verificação de Área Evacuada & $x$ & & Feito por bombeiros \\
\hline Isolamento de Área Evacuada & $x$ & & Feito por bombeiros \\
\hline Confinamento e Combate a Incêndio & $x$ & & Feito por bombeiros \\
\hline Exercícios simulados $2 \mathrm{x}$ ao ano & & $x$ & Não possui \\
\hline Reunião após simulado & & $x$ & Não possui \\
\hline Planta de Emergência Interna & $x$ & & Planta falha, informações faltantes \\
\hline Planta de Emergência Externa & $x$ & & Planta falha, Informações faltantes \\
\hline Plantas em locais visíveis & $\mathrm{x}$ & & Ao lado da porta de saída \\
\hline $\begin{array}{l}\text { Verificação do funcionamento de } \\
\text { luminárias a cada } 90 \text { dias }\end{array}$ & & $x$ & Somente vistoria do CBMSC \\
\hline $\begin{array}{l}\text { Verificação de desobstrução das saídas de } \\
\text { emergência toda semana }\end{array}$ & & $x$ & Somente vistoria do CBMSC \\
\hline $\begin{array}{l}\text { Verificação de sinalização de evacuação a } \\
\text { cada } 90 \text { dias }\end{array}$ & & $x$ & Somente vistoria do CBMSC \\
\hline $\begin{array}{l}\text { Verificação a cada } 6 \text { meses das mangueiras } \\
\text { e hidrantes, e usa-los pelo menos em um }\end{array}$ & & $x$ & Somente vistoria do CBMSC \\
\hline
\end{tabular}


simulado ao ano

Verificação da central de alarme a cada 90 dias, e aciona-lo em caso de simulados

Fonte: O próprio autor

Pode-se observar através do preenchimento da lista anterior, que existe um plano de emergência, porém existem várias considerações a serem feitas, devido ao tipo de edificação e a quantidade de funcionários fixos no local, segundo IN 001 (CBMSC, 2015), é necessário conter um brigadista de incêndio voluntario, foi entrado em contato com a parte administrativa e constado que os mesmos não possuem brigadista voluntário no momento, o qual seria responsável pela análise da situação do incêndio, verificação dos riscos existentes e eliminação dos mesmos, e inclusive auxiliar a evacuação do local até a chegada dos bombeiros.

No momento a Uniarp não conta com um brigadista de incêndio voluntário, porém está em busca de realizar todas as propostas e exigências do CBMSC. A sugestão de melhoria quanto a brigada, seria eles encontrarem uma pessoa para fazer o papel de um brigadista de incêndio, fornecer o devido treinamento e habilitação para que possa estar atendendo as necessidades não só do Bloco D mas também da Universidade como um todo.

Outra questão, é a inexistência dos simulados de incêndio, que devem ser feitos a cada 6 meses, os quais servem para treinar e orientar a população fixa do local (estudantes, professores, etc...), estes simulados consistem em promover um evento que envolva todos os procedimentos em caso de incêndio, desde a análise da situação, o foco de incêndio até a evacuação total da edificação, bem como a realocação da população após o simulado, revendo pontos importantes que precisam ser melhorados, como por exemplo, se houve tumulto, como pode ser resolvido no próximo simulado, lembrando que a população do local não saberá realmente o que vai estar acontecendo, ou seja, o evento é totalmente real aos olhos da população fixa.

Segundo Informações da Uniarp, os simulados estão sendo programados para primeira execução no primeiro semestre do ano de 2020, como sugestão de melhoria e auxilio para realização destes simulados, seria de extrema importância um mini treinamento para a população fixa, e móvel desta edificação, como por 
exemplo, uma cartilha informativa aonde contém todos os passos a serem tomados assim que for identificado algum foco de incêndio na edificação, no qual pode ser disponibilizado em arquivo digital, através do totem (localizado em frente à farmácia escola), portal acadêmico e acervo online, e também poderá ser disponibilizada de forma analógica nas dependências da biblioteca da Universidade.

As plantas de Emergência têm grande importância na orientação da população fixa do imóvel, pois, só vão prestar atenção em um extintor quando precisarem dele, a planta tem como finalidade demonstrar a rota de fuga.

A planta de emergência interna deverá indicar o caminho a ser percorrido até o encontro de uma saída de emergência, podendo ser escadas, rampas, ou até mesmo uma porta de saída, não esquecendo de indicar na planta o local exato dos equipamentos de proteção contra incêndio, como o extintor, hidrante e acionador manual de incêndio. A planta de emergência externa, consiste em todos os itens da planta de emergência interna, tendo inclusão do ponto de encontro, que será aonde toda a população irá se encontrar assim que evacuada a edificação, considerando este, como área segura longe dos riscos de incêndio. Abaixo está representada uma planta fixada no bloco $D$, na qual, não contém os requisitos acima citados.

Sugere-se que as plantas de emergência sejam revisadas garantindo que possuam todos os requisitos propostos pela normativa. 
Figura 1: Planta de Emergência Interna Atual

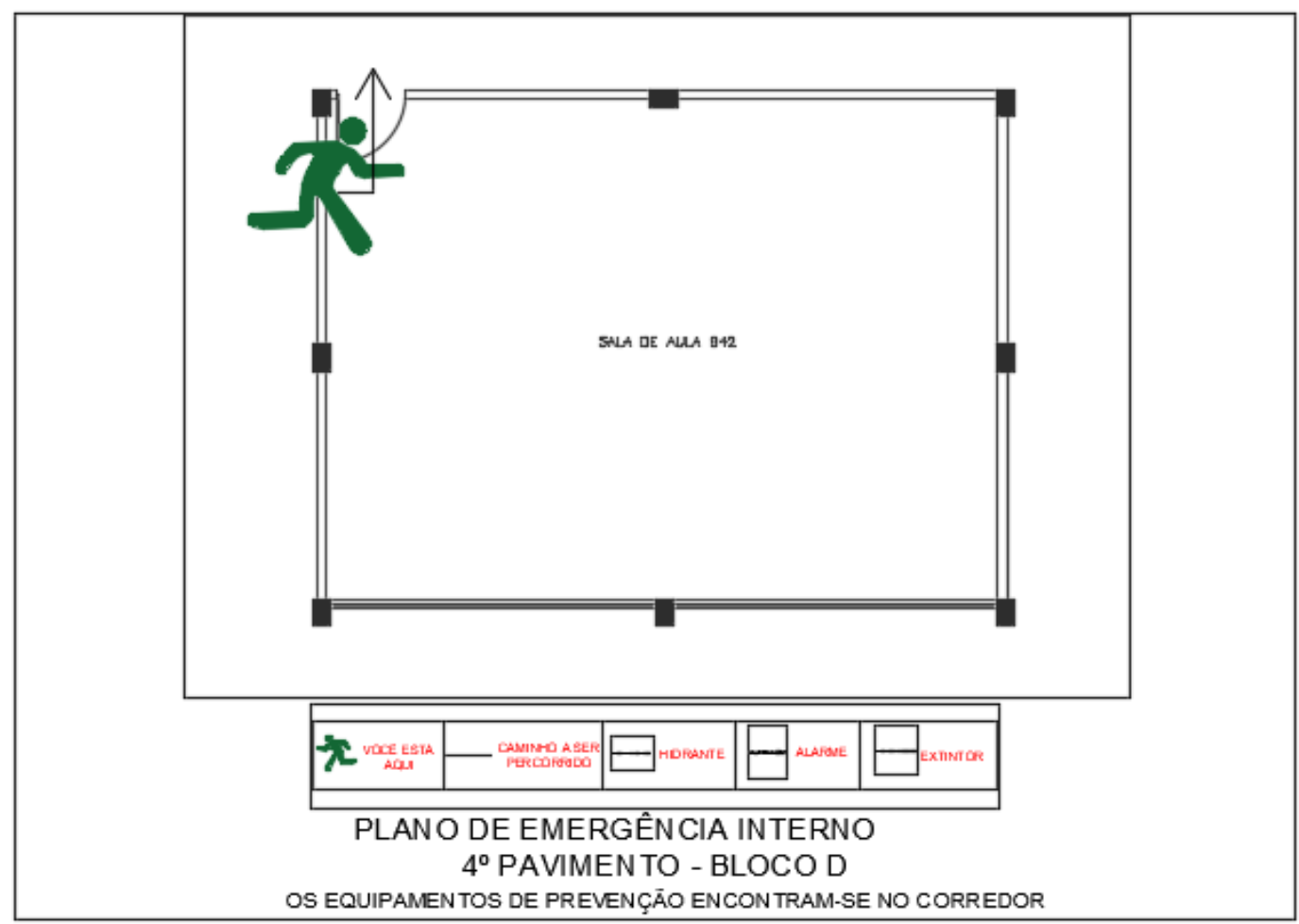

Fonte: UNIARP, 2019

Os equipamentos de Prevenção de incêndio deverão ser verificados periodicamente, e na visita in loco foram observadas luminárias de emergência penduradas por suas tomadas, ao invés de fixadas acima da abertura na sala de aula, conforme figura 2, considera-se, portanto que a inspeção de equipamentos de emergência é feita somente pelas inspeções do CBMSC que são realizadas uma vez por ano.

Sugere-se para melhoria, que a vistoria seja mais rigorosa quanto aos equipamentos de emergência para que não ocorram imprevistos, além de poder danificar o equipamento pode também acabar causando danos em pessoas que passam por ali. 
Figura 22: Luminária de Emergência Pendurada

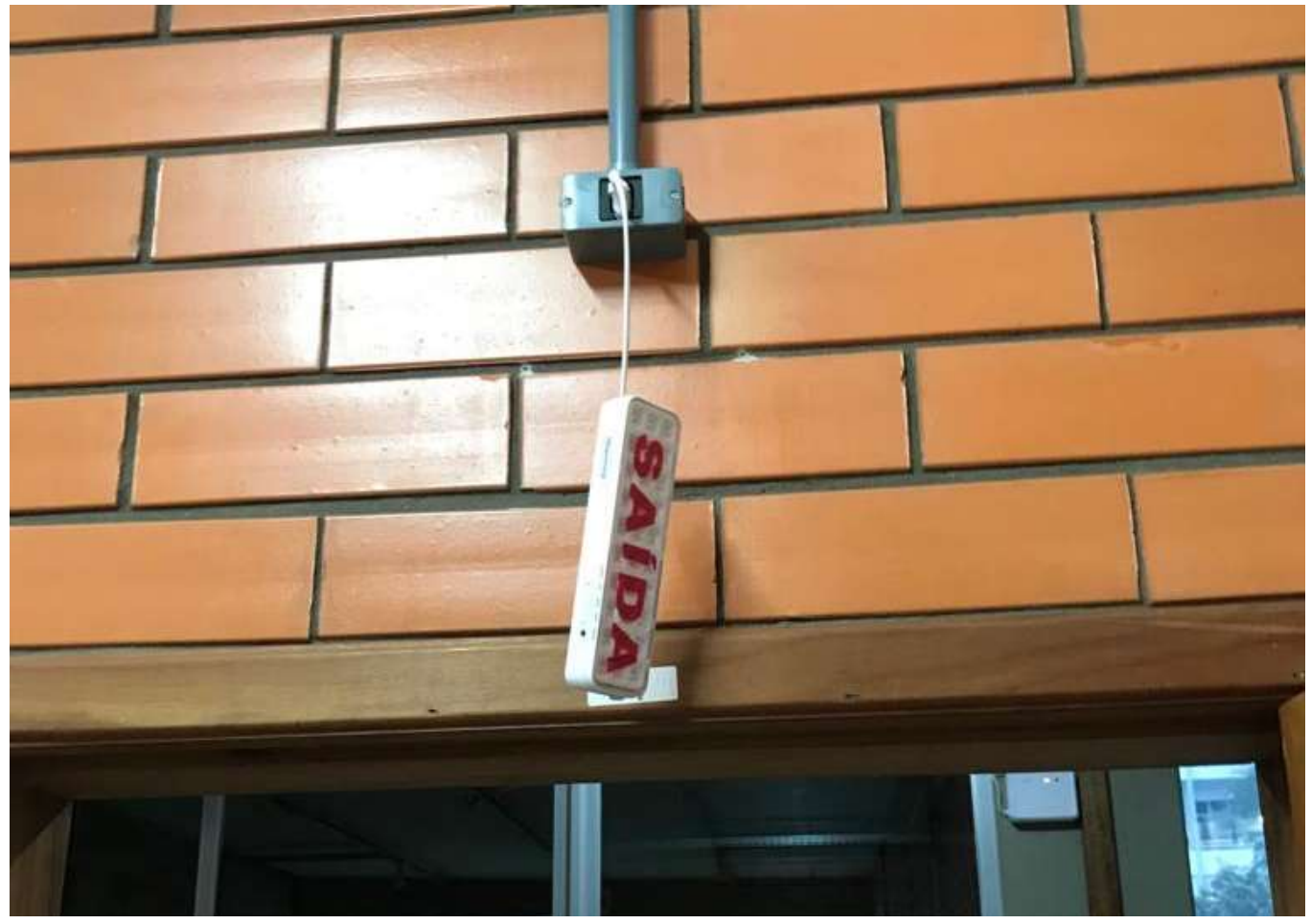

Fonte: O Próprio Autor

O Quadro abaixo é em relação ao preenchimento da lista de verificação quanto aos sistemas de iluminação de emergência presentes no bloco D da Uniarp, conforme IN 011(CBMSC, 2017). 
Quadro 2: Preenchimento Lista de Verificação de Iluminação de Emergência

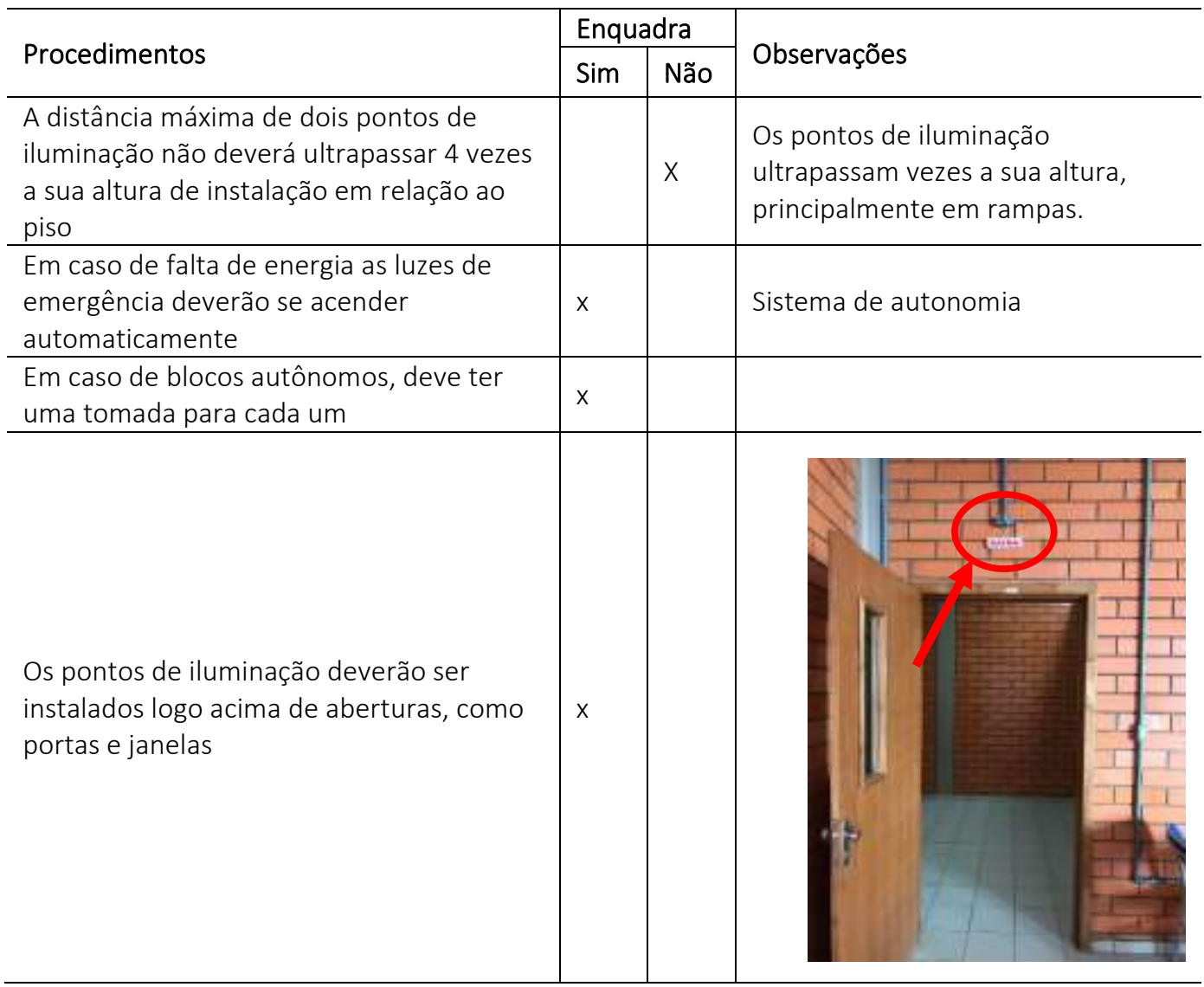

Fonte: O próprio autor

Através da Visita in loco foi observado que a quantia de luminárias nas rampas é insuficiente segundo a IN 011(CBMSC, 2017), a distância entre elas não deve ultrapassar 4 vezes a altura de sua instalação, sendo a altura da sua instalação 2,15 m e a distância entre as luminárias de aproximadamente 20 m conclui-se que a iluminação é insuficiente. Sugere-se como opção de melhoria aumentar a quantidade de luminárias e não deixar que a distância entre elas ultrapasse 8,6 m.

Seguindo adiante temos a verificação do Sistema de Alarme e Detecção de Incêndio na edificação do Bloco D da Uniarp com base na IN 012 (CBMSC, 2018). 
Quadro 3: Preenchimento Lista de Verificação de Sistema de Alarme e Detecção de Incêndio

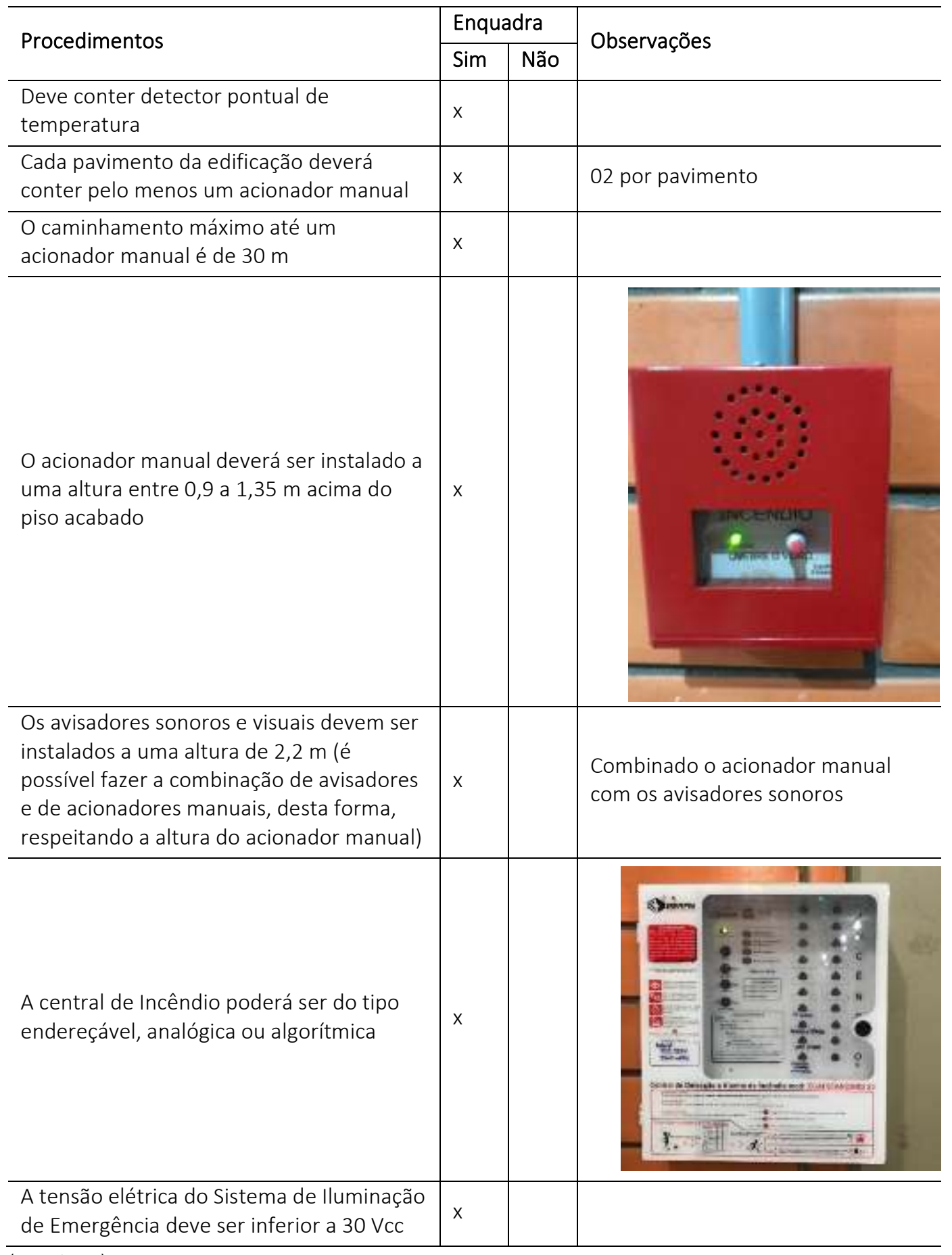

(Continua) 
Quadro 3: Preenchimento Lista de Verificação de Sistema de Alarme e Detecção de Incêndio

\begin{tabular}{l|l|l|l}
\hline \multirow{2}{*}{ Procedimentos } & \multicolumn{2}{|l|}{ Enquadra } & \multirow{2}{*}{ Observações } \\
\cline { 2 - 4 } & Sim & Não & \\
\hline $\begin{array}{l}\text { A central de alarme deverá ser instalada } \\
\text { em local com vigilância }\end{array}$ & & $x$ & $\begin{array}{l}\text { Vigilância falha, aconselharia } \\
\text { colocar na sala dos guardas, no } \\
\text { momento a mesma se encontra no } \\
1 \text { o pavimento do Bloco D }\end{array}$ \\
\hline $\begin{array}{l}\text { A autonomia das fontes de alimentação do } \\
\text { sistema de iluminação de emergência deve } \\
\text { conter autonomia mínima de } 1 \text { hora }\end{array}$ & $x$ & & \\
\hline $\begin{array}{l}\text { A autonomia das fontes de alimentação do } \\
\text { sistema de iluminação de emergência deve } \\
\text { conter autonomia mínima de } 1 \text { hora }\end{array}$ & $x$ & & \\
\hline
\end{tabular}

Fonte: O próprio autor

Quanto a verificação do sistema de Alarme e detecção de incêndio foi identificado que a central de alarme de incêndio está localizada no primeiro pavimento do Bloco D da Uniarp, caracterizada por passagem de estudantes e professores, sem vigilância fixa, onde aconselha-se instalar um aviso sonoro ou luminoso juntamente com a guarita, para que pudesse ficar em melhor supervisão; considerando manter a posição original, ao contrário deveria ser revisto todo o projeto de instalação central do alarme

Abaixo segue verificação da IN 013 (CBMSC, 2018) Sinalização de Abandono de Local, com relação à análise feita in loco do Bloco D da UNIARP. 
Quadro 4: Preenchimento Lista de Verificação de Sinalização de Abandono de Local

\begin{tabular}{|c|c|c|c|}
\hline \multirow{2}{*}{ Procedimentos } & \multicolumn{2}{|c|}{ Enquadra } & \multirow{2}{*}{ Observações } \\
\hline & Sim & Não & \\
\hline $\begin{array}{l}\text { Deverá indicar todos os obstáculos que } \\
\text { possuem na edificação, a cada ponto da } \\
\text { Sinalização deverá ser visível o próximo } \\
\text { ponto }\end{array}$ & & $x$ & Sinalização falha \\
\hline $\begin{array}{l}\text { A sinalização deverá ter autonomia de no } \\
\text { mínimo } 1 \text { hora }\end{array}$ & $x$ & & \\
\hline $\begin{array}{l}\text { A altura de instalação das sinalizações de } \\
\text { abandono de local é acima das aberturas } \\
\text { do ambiente }\end{array}$ & $x$ & & \\
\hline $\begin{array}{l}\text { Se for o caso, Placa fotoluminescente, } \\
\text { escrito SAÍDA, juntamente com seta } \\
\text { indicando a saída, com fundo na cor verde, } \\
\text { possuir mensagens e símbolos na cor } \\
\text { branca. }\end{array}$ & & $x$ & Enquadra no próximo item \\
\hline $\begin{array}{l}\text { Se for o caso adotar placa luminosa, a } \\
\text { mesma deverá conter a palavra saída na } \\
\text { cor vermelha ou verde, com seta } \\
\text { indicando a direção da saída, fundo branco } \\
\text { leitoso e ser de acrílico ou material similar }\end{array}$ & $x$ & & AÍDA \\
\hline $\begin{array}{l}\text { A placa luminosa deverá possuir fonte de } \\
\text { energia }\end{array}$ & $x$ & & \\
\hline $\begin{array}{l}\text { As placas luminosas alimentadas por bloco } \\
\text { autônomo deverão ter uma tomada } \\
\text { exclusiva, para cada bloco. }\end{array}$ & $x$ & & \\
\hline
\end{tabular}

Fonte: O próprio autor

Segundo IN 013 (CBMSC, 2018) a sinalização para abandono de local deverá ser útil na evacuação, devendo obrigatoriamente ser possível observar através de uma placa de sinalização o próximo passo a ser tomado, deste modo, conclui-se que o bloco $D$ da Uniarp é falho quanto a sinalização de abandono de 
local.

Uma sugestão válida é estar fixando placas verdes com flechas indicativas e escrita saída em branco (conforme figura 3), para melhorar a sinalização de abandono de local, providenciar também placas indicativas nos locais de encontro, para melhor visualização.

Figura 3: Placa de Sinalização de Saída

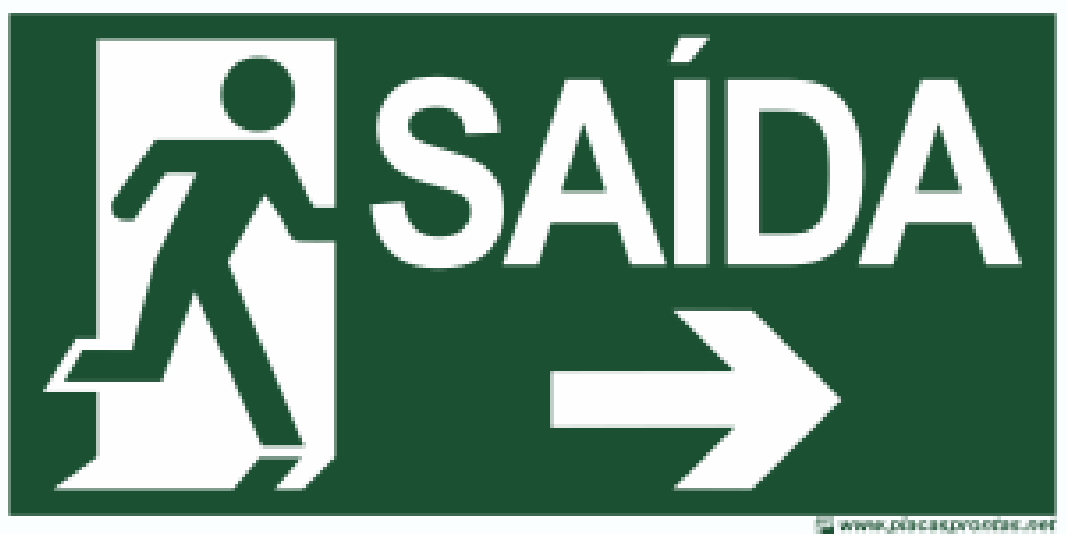

Fonte: Placas Prontas, 2019

Segundo IN 028 (CBMSC, 2014), o Bloco D da UNIARP Necessita de um Brigadista Voluntário, para isso foi realizado um contato com a administração da Universidade e coletado os dados presentes no Quadro 5 abaixo

Quadro 5: Preenchimento Lista de Verificação de Brigada de Incêndio

\begin{tabular}{l|l|l|l}
\hline \multirow{2}{*}{ Procedimentos } & \multicolumn{2}{|l|}{ Enquadra } & \multirow{2}{*}{ Observações } \\
\cline { 2 - 3 } & Sim & Não & \\
\hline $\begin{array}{l}\text { Deverá conter } 1 \text { brigadista voluntário, o } \\
\text { qual deverá combater princípios de } \\
\text { incêndio, e auxiliar na evacuação do local }\end{array}$ & & $x$ & Não possui brigadista voluntário \\
\hline
\end{tabular}

Fonte: O próprio autor

Segundo informações no momento não existe um brigadista de incêndio no local, porém pretendem regularizar o quanto antes, pois a Uniarp sempre está em busca de melhorias para seus ocupantes. 


\section{CONCLUSÃO}

O fogo é originado de um combustível em ação a um comburente, quando há uma fonte de calor, ele pode ser continuado ocasionando a reação em cadeia, se transformado desta forma em um incêndio que poderá ser de grande ou pequena escala, dependendo sempre da carga de incêndio presente na edificação.

Para prevenção de incêndios, nos dias de hoje, tem-se como auxilio diversas normativas disponibilizadas pelo CBMSC, através destas normativas, existem possibilidades de reconhecimento de requisitos mínimos para uma edificação nova, e também para a que já é existente, o Projeto Preventivo Contra Incêndio-PPCl é um grande aliado para a prevenção de incêndio em edificações, se elaborado com eficiência o mesmo traz resultados satisfatórios.

O desenvolvimento do presente estudo possibilitou a conferência de normativas atuais do estado de Santa Catarina, referente a prevenção de Incêndios, através dessas foram elaboradas listas de verificações do Bloco D da Uniarp, Campus Caçador, listando em especial o que é exigido pelas normativas em casos de edificações do tipo escolar geral, dando a possibilidade da análise diagnóstica do Plano de Emergência.

Através da análise diagnóstica foram observados alguns itens importantes, como por exemplo, a necessidade de reavaliar as plantas de emergência existentes, para complementar com maiores informações para os ocupantes da edificação, bem como, a necessidade do simulado de incêndio, que segundo informações já está sendo programado para o primeiro semestre do ano de 2020, como proposta de auxiliar no processo do simulado, venho propor através deste, a distribuição de cartilha de procedimentos, que poderá ser disponibilizada através de arquivo digital, por meio do totem e portal acadêmico, ou analógico através da biblioteca.

Conclui-se ainda que, é de extrema importância a efetivação do treinamento para a comunidade acadêmica, afim de prepara-la para seguir os procedimentos indicados nos folders analógicos ou digitais, efetivando as medidas necessárias para o combate ao incêndio. Ainda se indica a participação da CIPA (Comissão Interna de Prevenção de Acidentes) da instituição neste processo.

Espera-se que o estudo de caso apresentado neste artigo sirva de iniciativa 
para que outras instituições verifiquem o atendimento dos critérios normativos na integra, adequando-se as características construtivas de seus espaços.

\section{REFERÊNCIAS}

ASSOCIAÇÃO BRASILEIRA DE NORMAS TÉCNICAS. NBR 15219: Plano de emergência contra incêndio - Requisitos. 1 ed. Rio de Janeiro, 2005.

CAMILLO JÚNIOR, Abel Batista. Manual de Prevenção e Combate a Incêndios. 15. ed. Sao Paulo: Senac, 2013. 247 p.

CORPO DE BOMBEIROS MILITAR DE SANTA CATARINA. IN 001: Da Atividade Técnica. Santa Catarina, 2015. 72 p. Disponível em:

<https://dat.cbm.sc.gov.br/images/arquivo_pdf/IN/Em_vigor/IN_001_Da_Ativida de_Tecnica_17abril2015.pdf>. Acesso em: 01 abr. 2019.

CORPO DE BOMBEIROS MILITAR DE SANTA CATARINA. IN 005: Edificações Existentes. Santa Catarina, 2015. 32 p. Disponível em: $<$ https://dat.cbm.sc.gov.br/images/arquivo_pdf/IN/Em_vigor/IN_005_Edificaes_E xistentes_-30abril2015.pdf>. Acesso em: 01 abr. 2019.

CORPO DE BOMBEIROS MILITAR DE SANTA CATARINA. IN 006: Sistema Preventivo por Extintores. Santa Catarina, 2018. 7 p. Disponível em:

<https://dat.cbm.sc.gov.br/images/arquivo_pdf/IN/Em_vigor/IN_006_SPE_18abril 2018.pdf>. Acesso em: 01 abr. 2019.

CORPO DE BOMBEIROS MILITAR DE SANTA CATARINA. IN 007: Sistema hidráulico preventivo. Santa Catarina, 2017. 19 p. Disponível em:

<https://dat.cbm.sc.gov.br/images/arquivo_pdf/IN/Em_vigor/IN_007_SHP_01ago 2017.pdf>. Acesso em: 02 abr. 2019.

CORPO DE BOMBEIROS MILITAR DE SANTA CATARINA. IN 009: Sistema de saídas de emergência. Santa Catarina, 2014. 46 p. Disponível em:

$<$ https://dat.cbm.sc.gov.br/images/arquivo_pdf/IN/Em_vigor/IN_009_Saidas_de_ Emergncia_28mar2014.pdf>. Acesso em: 02 abr. 2019.

CORPO DE BOMBEIROS MILITAR DE SANTA CATARINA. IN 011: Sistema de iluminação de emergência. Santa Catarina, 2018. 7 p. Disponível em:

$<$ https://dat.cbm.sc.gov.br/images/arquivo_pdf/IN/Em_vigor/IN_011_SIE_18abr2 
018.pdf>. Acesso em: 03 abr. 2019.

CORPO DE BOMBEIROS MILITAR DE SANTA CATARINA. IN 012: Sistema de alarme e detecção de incêndio. Santa Catarina, 2018. 10 p. Disponível em:

<https://dat.cbm.sc.gov.br/images/arquivo_pdf/IN/Em_vigor/IN_012_SADI_31jan 2018_NT-38_NT42.pdf>. Acesso em: 04 abr. 2019.

CORPO DE BOMBEIROS MILITAR DE SANTA CATARINA. IN 013: Sinalização para abandono de local. Santa Catarina, 2018. 10 p. Disponível em:

<https://dat.cbm.sc.gov.br/images/arquivo_pdf/IN/Em_vigor/IN_013_SAL_16out 2018-1.pdf>. Acesso em: 04 abr. 2019.

CORPO DE BOMBEIROS MILITAR DE SANTA CATARINA. IN 018: Controle de materiais de revestimento e acabamento. Santa Catarina, 2016. 14 p. Disponível em:

<https://dat.cbm.sc.gov.br/images/arquivo_pdf/IN/Em_vigor/IN_018_Controle_ Materiais_Acabamento_12jan2016.pdf>. Acesso em: 07 abr. 2019.

CORPO DE BOMBEIROS MILITAR DE SANTA CATARINA. IN 028: Brigada de incêndio. Santa Catarina, 2014. 24 p. Disponível em:

<https://dat.cbm.sc.gov.br/images/arquivo_pdf/IN/Em_vigor/IN_028_Brigada_de _Incndio_28mar2014.pdf>. Acesso em: 07 abr. 2019.

CORPO DE BOMBEIROS MILITAR DE SANTA CATARINA. IN 031: Plano de emergência. Santa Catarina, 2014. 11 p. Disponível em:

<https://dat.cbm.sc.gov.br/images/arquivo_pdf/IN/Em_vigor/IN_031_Plano_de_E mergncia_28mar2014.pdf>. Acesso em: 07 abr. 2019. 